\title{
BMJ Open Does occupational distress raise the risk of alcohol use, binge-eating, ill health and sleep problems among medical doctors? A UK cross-sectional study
}

To cite: Medisauskaite A, Kamau C. Does occupational distress raise the risk of alcohol use, binge-eating, ill health and sleep problems among medical doctors? A UK crosssectional study. BMJ Open 2019;9:e027362. doi:10.1136/ bmjopen-2018-027362

- Prepublication history for this paper is available online. To view these files, please visit the journal online (http://dx.doi. org/10.1136/bmjopen-2018027362).

Received 14 August 2018 Revised 23 February 2019 Accepted 12 April 2019

\section{Check for updates}

\section{(C) Author(s) (or their} employer(s)) 2019. Re-use permitted under CC BY-NC. No commercial re-use. See rights and permissions. Published by BMJ.

${ }^{1}$ Research Department of Medical Education, UCL, London, UK

2Department of Organizational Psychology, Birkbeck, University of London, London, UK

Correspondence to Dr Asta Medisauskaite; a.medisauskaite@ucl.ac.uk

\section{ABSTRACT}

Objectives This study aims to assess the prevalence of health problems (eg, insomnia, binge-eating, substance use and ill health) among UK doctors and to investigate whether occupational distress increases the risk of health problems. Design This study reports the analysis of data collected at the baseline stage of a randomised controlled trial (protocol \#NCT02838290).

Setting Doctors were invited through medical Royal Colleges, the British Medical Association's research panel and a random selection of NHS trusts across various UK regions.

Participants 417 UK doctors with an equivalent split of gender (48\% males) and seniority (49\% consultants).

Main outcomes and measures Outcomes were sleep problems (eg, insomnia), alcohol/drug use (eg, bingedrinking), ill health (eg, backache) and binge-eating (eg, uncontrollable eating). Predictor variables were occupational distress (psychiatric morbidity, burnout, job effort, work-life imbalance, coping with stress through self-blame or substances) and work factors (workplace and years practising medicine).

Results $44 \%$ of doctors binge-drank and $5 \%$ met the criteria for alcohol dependence; $24 \%-29 \%$ experienced negative emotions after overeating and $8 \%$ had a bingeeating disorder; $20 \%-61 \%$ had some type of sleep problem and $12 \%$ had severe/moderate insomnia; $69 \%$ had fatigue and $19 \%-29 \%$ experienced other types of ill health problems. The results show that occupational distress and job factors increase the odds of doctors using substances, having sleep problems, presenting with frequent symptoms of ill health and binge-eating. For example, burnout increased the risk of all types of sleep problems, eg, difficulty falling/staying asleep, insomnia $(0 R \geq 1.344 ; p \leq 0.036)$. Even taking into consideration whether or not a doctor works in a hospital, the risk of health problems still rises when doctors have signs of occupational distress.

Conclusion Early recognition of occupational distress can prevent health problems among UK doctors that can reduce the quality of patient care because of sicknessrelated absence.

\section{INTRODUCTION}

Distress suffered by doctors has significant consequences for patient care. A recent

\section{Strengths and limitations of this study}

- This is the first study to explore a wide range of health problems among UK doctors and to examine work-related risk factors.

- The study was piloted by consulting doctors about the method before the study started.

- This is a cross-sectional study and therefore it is not possible to draw conclusions about causation.

- It was not possible to calculate the response rate because it was not clear if all NHS trusts and Royal Colleges who agreed to invite doctors to take part in this research did send out the invitations, and to how many doctors.

meta-analysis of 47 studies found that burned-out doctors were more likely to provide poor quality care because of reduced professionalism, and they were more likely to be associated with poor patient satisfaction and incidents that jeopardise patient safety. ${ }^{1}$ There is a high prevalence of distress among doctors in the UK, with a systematic review of 30 studies showing that $17 \%-52 \%$ of doctors have psychiatric morbidity, ${ }^{2}$ higher than the prevalence rate of $19 \%$ in the general population, ${ }^{3}$ and $31 \%-54 \%$ of doctors have a type of burnout called emotional exhaustion. ${ }^{2}$ Little is known, however, about whether occupational distress raises the risk of health problems (eg, insomnia, binge-drinking) that might compel doctors to be absent from work or take sick leave resulting in understaffing and a risk to patient safety.

Occupational distress can be described as a syndrome comprising burnout, depression, maladaptive coping strategies and other symptoms. ${ }^{4}$ The potential implications for risks to patient safety due to sickness-absence make it useful to investigate the impact of different types of occupational distress on the relative risk of: (a) behaviours that have an impact on doctors' health such as alcohol/drug use 
and binge-eating; (b) health issues such as sleep disturbances and daily or weekly symptoms of ill health (eg, headaches or fatigue). This is the first study to examine such a broad spectrum of health consequences among doctors. The other innovation of the current study is that, whereas many previous studies have sampled US doctors ${ }^{5}$ or individual specialties such as oncology ${ }^{4}$ and surgery, ${ }^{6}$ this study sheds new light on the impact of occupational distress on health problems among doctors in the UK.

\section{Does occupational distress increase the risk of doctors using alcohol or drugs?}

Workers experiencing occupational distress are more likely to regularly drink alcohol, binge-drink or use drugs as a method of coping. ${ }^{78}$ Doctors, on average, report equivalent or lower rates of alcohol abuse than the general population, ${ }^{9}$ but daily alcohol consumption or bingedrinking that does not meet the threshold for diagnosis of alcoholism is still problematic, ${ }^{10}{ }^{11}$ and symptomatic of psychological distress. In the USA, $10 \%$ of doctors drink alcohol daily and $8 \%$ report severe alcohol or drug misuse or dependence at some point in their lives. ${ }^{5}$ Prescription drug abuse is particularly problematic because doctors are up to five times more likely to use prescription drugs than the general population due to easier access or familiarity with prescription drugs, for example, $24 \%$ of US doctors use benzodiazepine and $40 \%$ use minor opiates. ${ }^{5}$ There are many reasons why doctors use substances-not all of which are to do with being distressed-therefore research is needed to clarify the proportion of doctors who use alcohol/drugs as a way of coping with occupational distress. The coping function of alcohol/drug use among doctors, as with the general population, is plausible because alcohol and many drugs have psychoactive properties, for example, prescription drugs such as benzodiazepine and opiates; illicit drugs such as Lysergic Acid Diethylamide (LSD). Occupational distress is known to predict alcohol misuse in the general population, ${ }^{7}$ but little is known about whether, for example, doctors with high levels of burnout are at greater risk of using alcohol or drugs (including prescription or legally purchased drugs), and whether other types of occupational distress (eg, psychiatric morbidity, negative coping strategies) have similar effects. Little is also known about the impact of other job factors such as work experience on the risk of doctors engaging in substance use.

\section{Does occupational distress increase the risk of doctors' binge-eating?}

Like alcohol or drug use, binge-eating is more prevalent among workers experiencing occupational distress ${ }^{12}$ but, unlike substance use, little is known about binge-eating rates among doctors and risk factors. Binge-eating can be defined as eating a larger amount of food than most people eat in one sitting and finding oneself unable to control one's eating. ${ }^{13}$ Binge-eating, like alcohol or drug use, is a common method of coping with psychological distress because eating offers an initial sense of comfort. ${ }^{14}{ }^{15}$ The initial comfort is, however, followed by feelings of shame or guilt, thus exacerbating distress. ${ }^{15}$ This is one of the first studies to assess the prevalence of binge-eating among UK doctors and to offer insights into whether doctors who binge-eat experience unpleasant emotions after bingeing. This study will also offer new insights into the impact of different types of occupational distress (eg, work-life imbalance) which, together with analysing substance abuse by doctors, will reveal the consequences of occupational distress for doctors' health-related behaviours.

\section{Does occupational distress increase the risk of doctors having} sleep disturbances?

There have been calls for research into the connection between sleep problems and doctors' health, ${ }^{16}$ but most previous studies have focused on sleep deprivation rather than sleep disturbances that have a psychological aetiology, for example, trouble falling/staying asleep due to worry. Sleep deprivation can be defined as the lack of the opportunity to sleep, or more simply as sleeping too few hours each day. Sleep deprivation is associated with depression, ${ }^{17} 18$ burnout, ${ }^{19}$ suicide risk ${ }^{18}$ and immunity or cardiovascular health problems ${ }^{20}$ among doctors but sleep deprivation in itself is not necessarily a sign of psychological distress. Doctors who work long shifts ${ }^{21}$ or lack block-scheduled shifts ${ }^{22}$ sleep too few hours because they have no choice. Therefore, rather than measuring sleep deprivation, this study measured types of sleep disturbance with a psychological aetiology such as trouble falling asleep, waking up prematurely because of worrying about work and insomnia. It is plausible that the risk of these types of sleep disturbance is higher among doctors suffering from work-life imbalance, psychiatric morbidity and other types of occupational distress. This study will evaluate whether UK doctors suffering from occupational distress have an increased risk of sleep disturbances.

\section{Does occupational distress increase the risk of doctors presenting with ill health?}

There is some research about the physical health of doctors in some specialties (eg, oncology), ${ }^{4}$ but research is needed to assess whether occupational distress predicts the risk of doctors from various specialties suffering from daily or frequent headaches, gastrointestinal problems and other physical symptoms. Physical health has a complex range of causes (eg, health behaviours, genetics and infections), but people who are distressed are more susceptible to infections because psychological distress weakens the immune system. ${ }^{23}$ The important question, therefore, is the relative risk of ill health symptoms, comparing doctors with and without occupational distress. We recognise that the physical health of doctors is shaped by a complex range of factors-only one of which is occupational distress-because working in a clinical environment can pose some risk to physical health. ${ }^{24}$ This study is one of the first to shed light on the impact of 
occupational distress on ill health symptoms among UK doctors.

\section{Study aims}

This study aims to assess whether doctors suffering from occupational distress have an increased risk of (i) using alcohol or drugs (illicit, non-illicit); (ii) binge-eating; (iii) having sleep disturbances and (iv) presenting with physical health symptoms. This study will extend previous literature about occupational distress in medicine, which has focused on burnout and psychiatric morbidity, ${ }^{2}$ by measuring and defining occupational distress in additional ways, or example, work-life imbalance, job effort, coping with stress through self-blame or through substance use, drawing on previous literature highlighting the multiple dimensions of occupational distress. ${ }^{4}$ This study will also provide new insights into the prevalence of alcohol/drug use, binge-eating, sleep and ill health problems among UK doctors, extending previous research about doctors from other countries or individual specialties. ${ }^{46}$

\section{METHOD}

\section{Patient and public involvement statement}

All questionnaires were valid, reliable measures selected from previous literature, but it was important to consult doctors about whether the types of occupational distress and health problems to be measured were relevant to doctors, and whether the instructions were clear. We thus consulted 15 doctors before the main study, using online software (Qualtrics). The pilot study sought the doctors' feedback (through open-ended questions) about the relevance and clarity of the questionnaires. Doctors gave generally positive feedback. Some minor amendments included revising the wording of demographic questions, questionnaire instructions and reducing the number of questionnaires to eliminate similar measures.

\section{Study design}

The research reported in this article is an analysis of data collected at the baseline stage of a randomised controlled trial (protocol \#NCT02838290) of the effect of an intervention on doctors' levels of occupational distress and health problems. The trial took place from July to November 2016. Due to the complexity of the trial, this paper reports a cross-sectional analysis of the baseline data.

\section{Participants and study size}

Doctors took part in this study online (Qualtrics). They learnt about the study through medical Royal Colleges, NHS trusts and the British Medical Association (BMA). To prevent selection bias based on specialty, we invited all Royal Colleges from which nine agreed to distribute information about the research to their members. To prevent selection bias due to an NHS trust's reputation we randomly selected 25\% NHS trusts. From the ones possible to reach, nine distributed invitations to this study. The third source of data was the BMA's research panel. The majority of UK medical doctors are members of the BMA and any of them can join the BMA's research panel; therefore, this panel represented a broad spectrum of doctors. All medical doctors working in the UK were included in the baseline data analysis.

\section{Measures}

Outcome measures: doctors completed a variety of questionnaires assessing health problems. In some cases, we analysed responses to individual items in addition to the average of whole questionnaires because this offered richer insights into the prevalence of certain types of substance misuse (eg, binge-drinking), different symptoms of ill health (eg, backache), different signs of bingeeating (eg, uncontrollable eating) and sleep disturbances (eg, trouble falling asleep). This also enabled a better understanding of what aspects of health problems are predicted by occupational distress.

1. Alcohol and drug use: alcohol dependence was assessed with the Patient Health Questionnaire ${ }^{25}$ and the alcohol use habits with three items from the Alcohol Use Disorder Identification Test. ${ }^{26}$ Two items from the Brief COPE questionnaire ${ }^{27}$ evaluated doctors' tendency to use substances as a stress coping strategy. Drug use list of 22 illicit and legal drugs was devised from the Commonly Abused Drugs Charts ${ }^{28}$ and the UK drug misuse declaration. ${ }^{29}$

2. Binge-eating habits: these were measured using the binge-eating disorder items from the Eating Disorder Diagnostic Scale (as a scale and separate items). ${ }^{30}$

3. Sleep disturbances: insomnia was measured with the Insomnia Severity Index (ISI; Cronbach's $\alpha=0.891$ ). ${ }^{31}$ Sleep problems were items derived from the Effort-Reward scale ${ }^{32}$ and ISI. ${ }^{31}$

4. Ill health symptoms: the Physical Symptom Inventory ${ }^{33}$ comprising 12 items was used to assess the frequency with which doctors experienced various symptoms.

Predictor measures: the predictor variables and measuring instruments captured different types of occupational distress and job factors:

1. Psychiatric morbidity: this was measured using the General Health Questionnaire-12 (GHQ-12; Cronbach's $\alpha=0.927) .{ }^{34}$ This measure of psychiatric morbidity was chosen instead of others (eg, Patient Health Questionnaire) because GHQ-12 was previously extensively used to examine working populations, ${ }^{3}$ including doctors. ${ }^{4}$

2. Burnout: emotional exhaustion from the Maslach Burnout Inventory ${ }^{35}$ was assessed in this study (Cronbach's $\alpha=0.905$ ). Emotional exhaustion was selected because previous research shows that it is the best predictor of stress-related health among the three burnout dimensions. ${ }^{36}$

3. Job effort: the Job Effort scale from the Effort-Reward scale $^{32}$ measured time pressure, interruptions and demands at work (Cronbach's $\alpha=0.770$ ). 
4. Work-life imbalance: this was measured using the Work-Family Conflict scale ${ }^{37}$ (Cronbach's $\alpha=0.934$ ).

5. Maladaptive coping strategies: two scales from the Brief COPE questionnaire ${ }^{27}$ were used: coping through substance use (Cronbach's $\alpha=0.872$ ), and coping through self-blame (Cronbach's $\alpha=0.783$ ).

6. Work experience: years working in medicine.

7. Work place type: doctors indicated whether they work in a hospital or other setting.

More information about the measures is presented in table 1 .

\section{Statistical methods}

Outcome variables were recoded into binary variables in order to distinguish between the presence and absence of a health problem and to identify factors that raise the risk of the symptom being present. The cut-off points where possible were identified from the literature (see citations within table 1). For sleep problems, we determined the cut-off points based on the guidance for the ISI. ${ }^{31}$ For each item doctors reporting moderate or severe sleep problems were noted as having the symptom present, and reporting no/mild sleep problems were noted as having the symptom absent. Doctors' responses about using substances to cope with stress were dichotomised as either not doing so, or using substances a little bit, to a medium extent or a lot. Frequency of drinking was divided into drinking alcohol less than two to three times a week and more than two to three times a week. Ill health symptoms were recoded such that the presence of each symptom meant experiencing once/twice per week or more often (see table 1 for more details). Logistic regression tested the impact of predictors on the odds of the outcomes using SPSS V.21 software.

\section{RESULTS}

In total, 417 UK doctors participated. The mean age was 47.23 years $(\mathrm{SD}=10.97)$, and there was an equivalent split of gender ( $48 \%$ males) and seniority (49\% consultants). We compared demographic characteristics of doctors in this study with doctors on the List of Registered Medical Practitioners (LRMP) ${ }^{3839}$ and the comparison showed that the current sample largely mirrors the demographics of UK medical doctors in terms of the proportion of doctors by gender, age, grade and specialty, except that there was a higher representation of consultants and public health doctors than the proportions within the LRMP (table 2).

Table 1 shows the prevalence and descriptive statistics of different types of occupational distress, for example, $32.7 \%$ of doctors had psychiatric morbidity and 55.3\% were emotionally exhausted.

\section{How many doctors use alcohol or drugs?}

Table 1 shows that $53 \%$ of doctors drank alcohol $\geq 2$ times a week, $27 \%$ consumed $\geq 3$ drinks on a typical day of drinking and $44 \%$ binge-drank by consuming $6+$ drinks on one occasion. Five per cent of doctors met the criteria for alcohol dependence, but the rest of doctors did not report significant impairments in their occupational or other functioning as a result of drinking alcohol. In terms of illicit/non-illicit drug use, $44 \%$ of doctors used some type of drugs but almost all were non-illicit drugs: $3 \%$ of doctors used prescription opioids, $2 \%$ used benzodiazepines, $5 \%$ used sleep medication, $5 \%$ smoked tobacco, $7 \%$ used herbal or homeopathic remedies and $35 \%$ used over-the-counter medicines. Illegal drug use was rare: only one doctor reported cocaine use and one doctor used amyl nitrite. No doctor reported using amphetamines, anabolic steroids, cannabis, ecstasy, heroin, ketamine, khat, LSD, magic mushrooms, mephedrone, methadone, methamphetamine or tranquillisers.

\section{Are distressed doctors more likely to use alcohol/drugs?}

Coping with stress was the reason given by many doctors for drinking alcohol or taking drugs, with $34 \%$ saying that they used substances in order to feel better, and $22 \%$ used substances to help them get through stressful events. Table 3 shows logistic regression results analysing the effects of occupational distress and job factors on alcohol and drug use. The model significance testing shows that the predictors significantly explained variance in doctors using substances to help them get through something (6\%), drinking alcohol frequently $(38 \%)$ and large amounts (12\%), binge-drinking (28\%) and being alcohol dependent (28\%). The predictors did not explain variance in drug use and doctors using substances to feel better $(p>0.05)$. Doctors who coped with stress by using substances had a higher risk of frequent alcohol use, binge-drinking, alcohol dependence and drug use $(p \leq 0.022)$. The results also show that having more experience working in medicine raised the risk of a doctor drinking alcohol frequently $(\mathrm{OR}=1.036 ; \mathrm{p}=0.002)$, but lowered the risk of bingedrinking $(\mathrm{OR}=0.970 ; \mathrm{p}=0.007)$. Doctors who worked in a hospital were more likely to drink high amounts of alcohol on a typical day of drinking and to binge-drink $(\mathrm{OR} \geq 1.672 ; \mathrm{p} \leq 0.044)$. Doctors who reacted to stress by blaming themselves were more likely to use substances to get through something $(\mathrm{OR}=1.374 ; \mathrm{p}=0.039)$. Burnout, work-life imbalance and job effort were not significant unique predictors of substance use, although the combined models were significant. The exception was psychiatric morbidity which had a significant unique effect of decreasing the risk of doctors drinking alcohol frequently $(\mathrm{OR}=0.478 ; \mathrm{p}=0.019)$.

\section{How many doctors binge-eat?}

Table 1 shows that $35 \%$ of doctors ate a large amount of food when they were not physically hungry, $31 \%$ ate until they felt uncomfortably full and 24\%-29\% of doctors experienced negative emotions after overeating such as embarrassment, disgust, depression or guilt. We found that $8 \%$ of doctors had a binge-eating disorder. 


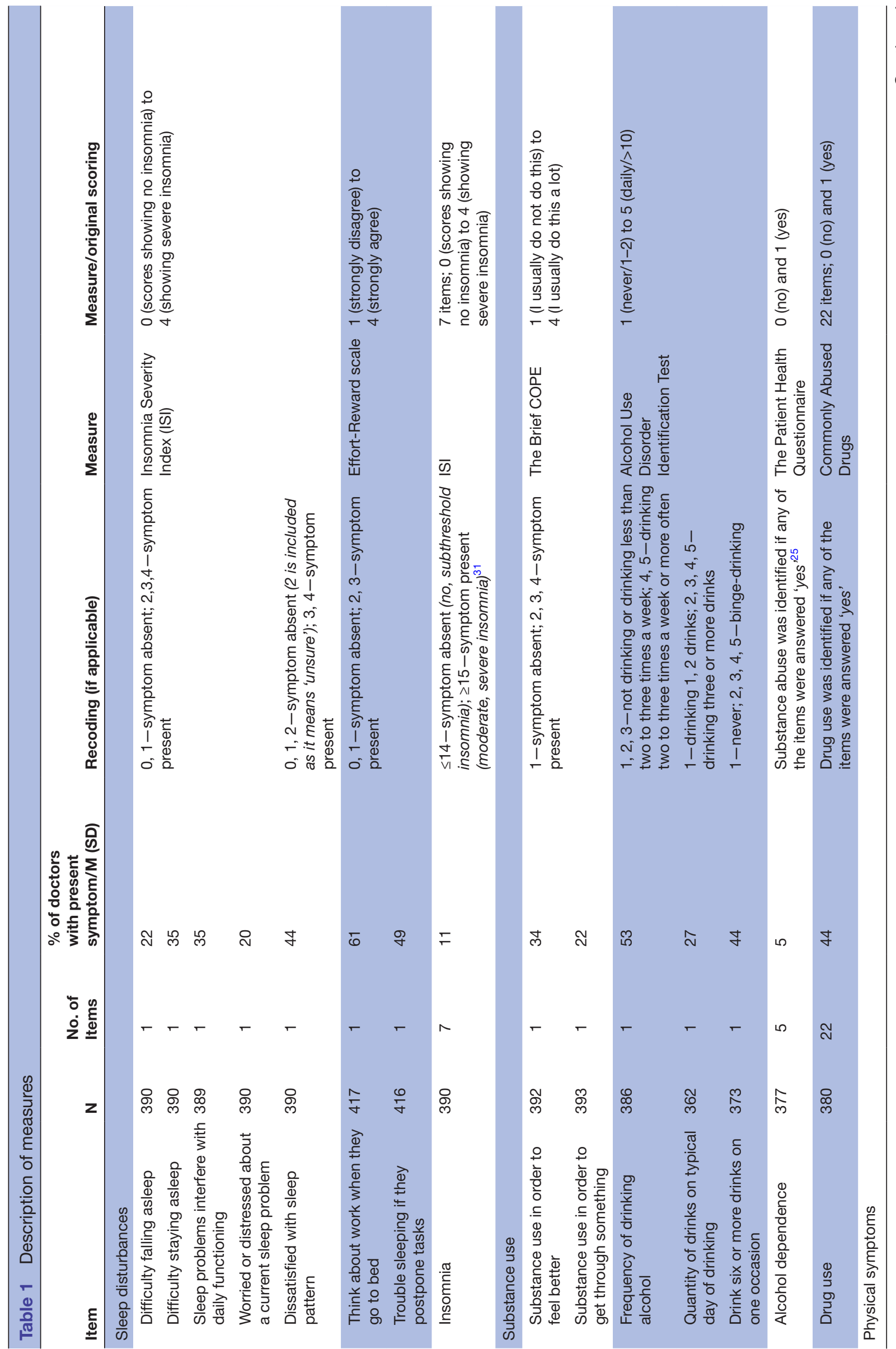




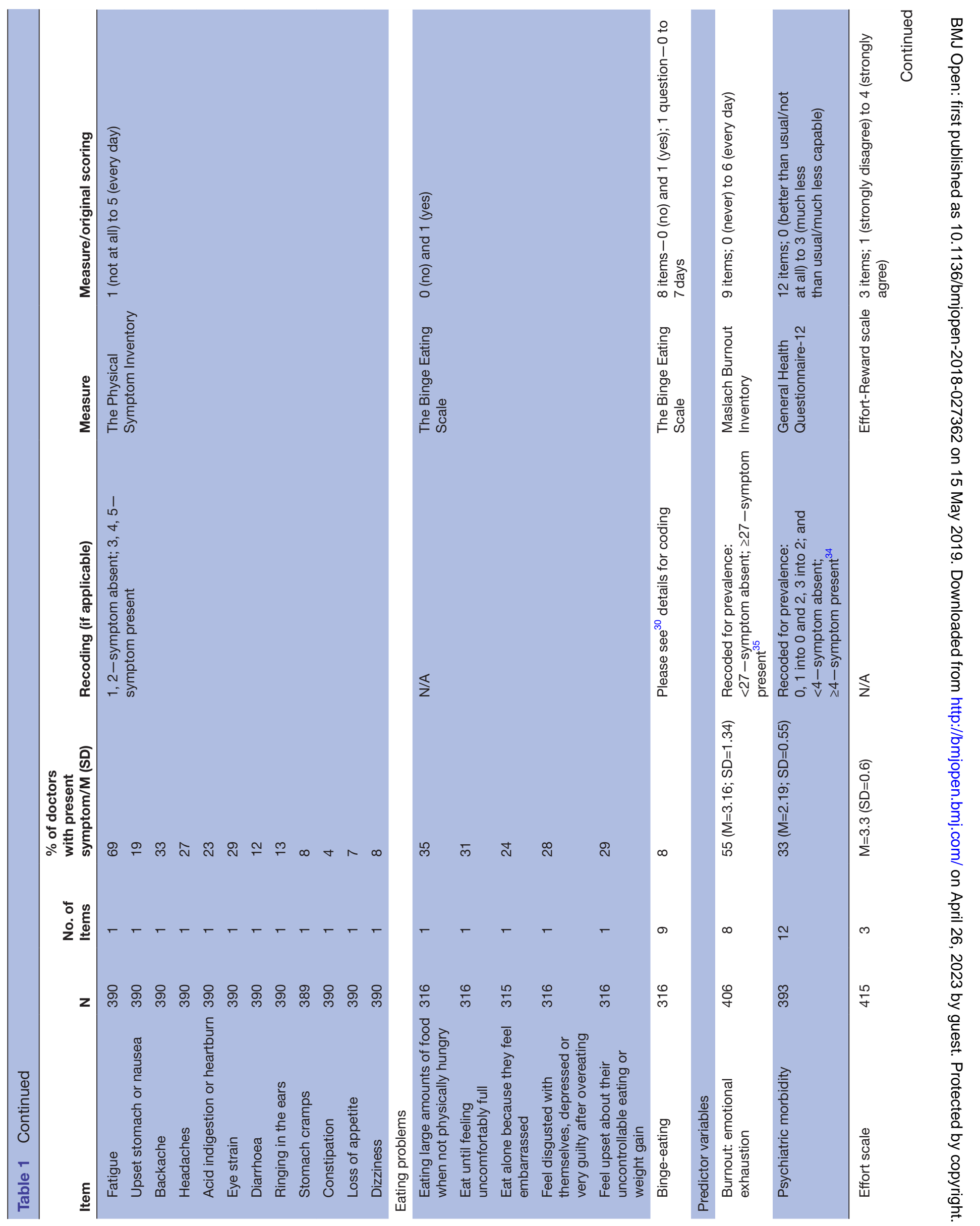




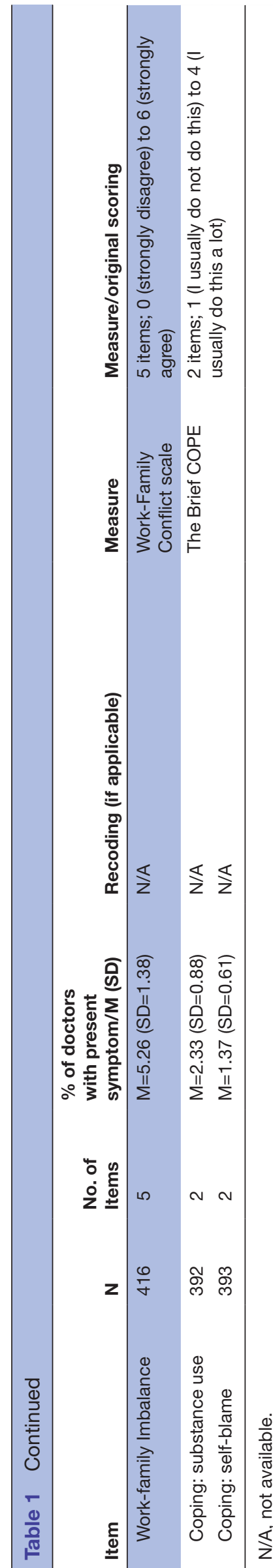

\section{Are distressed doctors more likely to binge-eat?}

Table 4 shows that all models tested were statistically significant and the predictors explained $8.1 \%-17.1 \%$ of variance in binge-eating habits $(\mathrm{p}<0.05)$. Types of occupational distress that, individually, significantly predicted binge-eating habits were: self-blaming, work-life imbalance and burnout. More experienced doctors were less likely to feel disgusted with themselves after binge-eating $(\mathrm{OR}=0.966 ; \mathrm{p}=0.009)$, as were doctors who worked in hospitals $(\mathrm{OR}=0.453 ; \mathrm{p}=0.008)$. Job effort lowered the risk of a binge-eating disorder $(\mathrm{OR}=0.179 ; \mathrm{p}<0.001)$. Psychiatric morbidity, by itself, did not predict binge-eating, and nor did coping with stress through substance use $(\mathrm{p}>0.05)$.

\section{How many doctors have sleep disturbances?}

Table 1 shows that $22 \%$ of doctors had difficulty falling asleep, $35 \%$ difficulty staying asleep, $44 \%$ were dissatisfied with their sleep pattern, $20 \%$ were worried or distressed about a current sleep problem and 35\% of doctors' sleep problems interfered with daily functioning. Thinking about work contributed to sleep problems; $61 \%$ of doctors thought about work when they went to bed and $49 \%$ had trouble sleeping if they postponed something they were supposed to do that day. The $\mathrm{ISI}^{31}$ showed that $12 \%$ of doctors had severe/moderate insomnia.

\section{Are distressed doctors more likely to have sleep disturbances?}

Logistic regression models predicting seven signs of sleep problems and insomnia are presented in table 5. All models were statistically significant explaining from $23.4 \%$ to $39.1 \%$ of variance, showing that occupational distress and job factors significantly predicted sleep disturbances among doctors. Doctors with psychiatric morbidity were more likely to have insomnia, difficulty falling/staying asleep, think about work when they went to bed, find that sleep problems interfered with their daily functioning $(O R \geq 2.117 ; p \leq 0.026)$, and burnout increased the risk of all seven sleep disturbances $(\mathrm{OR} \geq 1.344 ; \mathrm{p} \leq 0.036)$. Other significant unique predictors of sleep problems among doctors were: maladaptive coping with stress, work-life imbalance and working in a hospital $(\mathrm{p} \leq 0.030)$.

How many doctors suffer from daily or frequent ill health?

Sixty-nine per cent of doctors had fatigue and between $19 \%$ and $29 \%$ frequently experienced other type of ill health problems, for example, upset stomach, backache and headaches. Only $8 \%$ or fewer doctors reported frequent (daily/weekly) non-menstrual stomach cramps, constipation, appetite loss and dizziness, therefore these symptoms were not analysed using logistic regression.

\section{Are distressed doctors more likely to have daily or frequent ill health?}

Table 6 shows the logistic regression results that the odds of doctors suffering from frequent ill health are raised by occupational distress together with years practising medicine and working in a hospital. The predictors explained 
Table 2 Participants' sociodemographic characteristics

\begin{tabular}{|c|c|c|}
\hline Sociodemographic characteristics & $\%(n)$ or $M(S D)$ & LRMP \\
\hline Gender (male) & $48 \%(199)$ & $54.5 \%$ \\
\hline Age (years) & $47.23(10.97)$ & \\
\hline Under 30 & $7 \%(28)$ & $13 \%$ \\
\hline $30-49$ & $46 \%(190)$ & $59 \%$ \\
\hline Over 50 & $48 \%(197)$ & $28 \%$ \\
\hline Year of experience in medicine & $22.94(11.35)$ & N/A \\
\hline \multicolumn{3}{|l|}{ Grade } \\
\hline Junior doctor & $20 \%(82)$ & $21 \%$ \\
\hline General practitioner & $18 \%(75)$ & $23 \%$ \\
\hline Consultant & $49 \%(203)$ & $32 \%$ \\
\hline Other & $14 \%(57)$ & $23 \%$ \\
\hline \multicolumn{3}{|l|}{ Workplace } \\
\hline Community & $5 \%(21)$ & \\
\hline General practice & $15 \%(61)$ & \\
\hline Hospital & $58 \%(239)$ & N/A \\
\hline Multiple places & $15 \%(61)$ & \\
\hline Other & $8 \%(32)$ & \\
\hline \multicolumn{3}{|l|}{ Specialty } \\
\hline General practice & $17 \%(71)$ & $23 \%$ \\
\hline Public health & $12 \%(49)$ & $0.4 \%$ \\
\hline Anaesthetics and intensive care & $9 \%(39)$ & $8 \%$ \\
\hline Paediatrics & $7 \%(27)$ & $2 \%$ \\
\hline Emergency medicine & $6 \%(24)$ & $1 \%$ \\
\hline Psychiatry & $6 \%(25)$ & $3 \%$ \\
\hline Other & $44 \%(184)$ & \\
\hline \multicolumn{3}{|l|}{ Working hours } \\
\hline$\leq 40$ & $34 \%(141)$ & $\mathrm{N} / \mathrm{A}$ \\
\hline $41-50$ & $41 \%(170)$ & \\
\hline$>50$ & $15 \%(104)$ & \\
\hline
\end{tabular}

LRMP, List of Registered Medical Practitioners; N/A, not available.

$8 \%-35.2 \%$ of variance in doctors presenting with ill health symptoms; only the effects on back pain were non-significant $(p=0.083)$. Several types of occupational distress had significant unique effects, meaning that they individually predicted doctors' health. For instance, burnout raised the odds of doctors suffering from fatigue $(\mathrm{OR}=1.804 ; \mathrm{p}<0.001)$; job effort raised the odds of headaches $(\mathrm{OR}=1.905 ; \mathrm{p}=0.030)$; work-life imbalance raised the odds of diarrhoea $(\mathrm{OR}=1.717 ; \mathrm{p}=0.005)$ and psychiatric morbidity raised the odds of doctors suffering from fatigue, upset stomach or nausea, headaches, acid/indigestion/heartburn and eye strain $(\mathrm{OR} \geq 1.930 ; \mathrm{p} \leq 0.017)$. Working in a hospital did not, by itself, predict doctors' presentation of ill health symptoms, and nor did using substances to cope with stress $(p>0.05)$. More years of experience in medicine decreased the odds of doctors having fatigue, upset stomach or nausea and headaches
$(\mathrm{OR} \geq 0.963 ; \mathrm{p} \leq 0.024)$, but more experienced doctors had increased odds of ear ringing $(\mathrm{OR}=1.050 ; \mathrm{p}=0.002)$.

\section{DISCUSSION}

\section{Prevalence of occupational distress and health problems} among UK doctors

This study shows the prevalence of occupational distress and health problems such as ill health symptoms, and health-related problems (eg, substance use) among UK doctors. The results replicate a recent systematic review about the prevalence of burnout and psychiatric morbidity ${ }^{2}$ by finding that $32.7 \%$ of UK doctors have psychiatric morbidity and $55.3 \%$ a type of burnout called emotional exhaustion while providing new evidence about the prevalence of types of problems that were unrepresented in previous literature. The results showed 


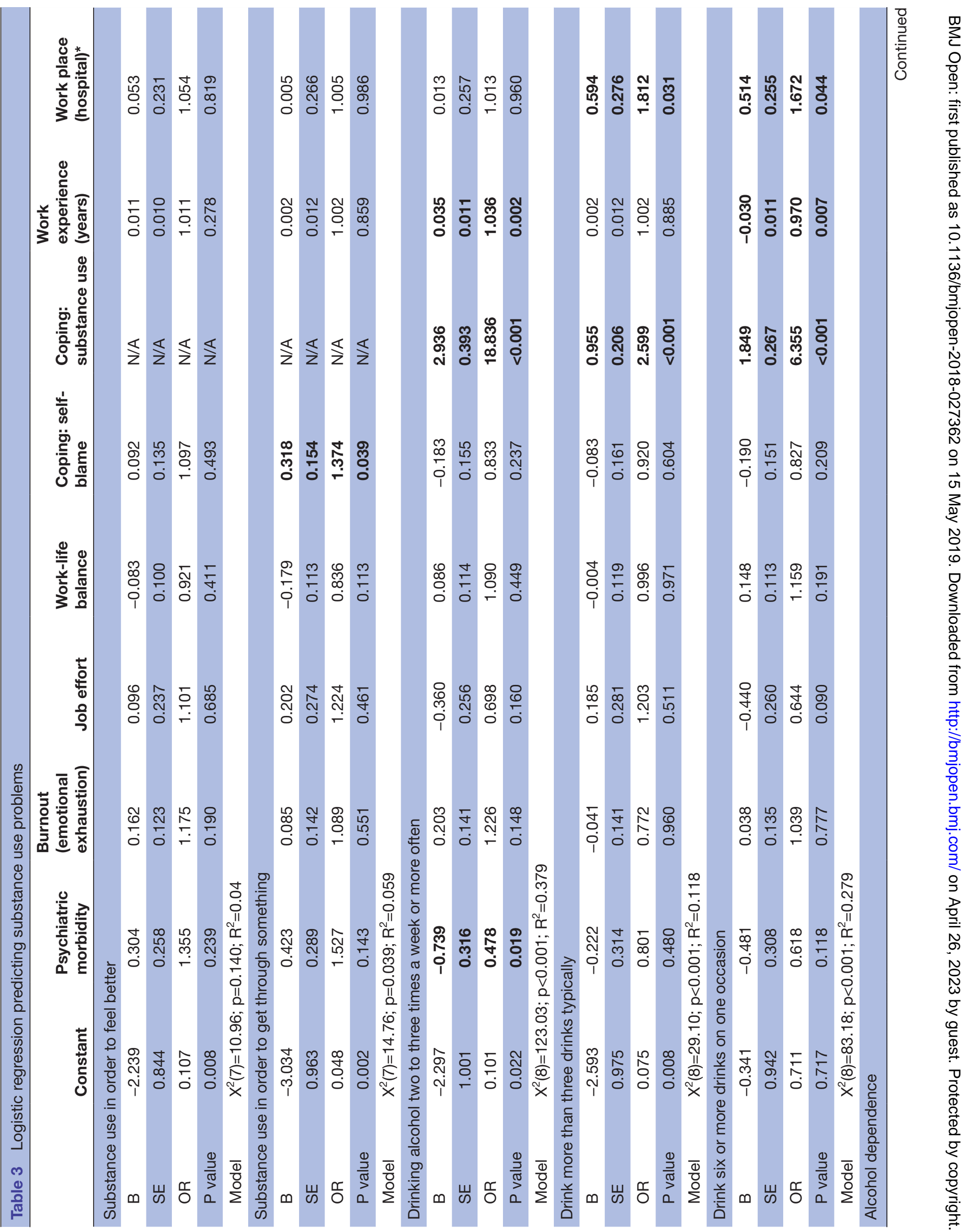




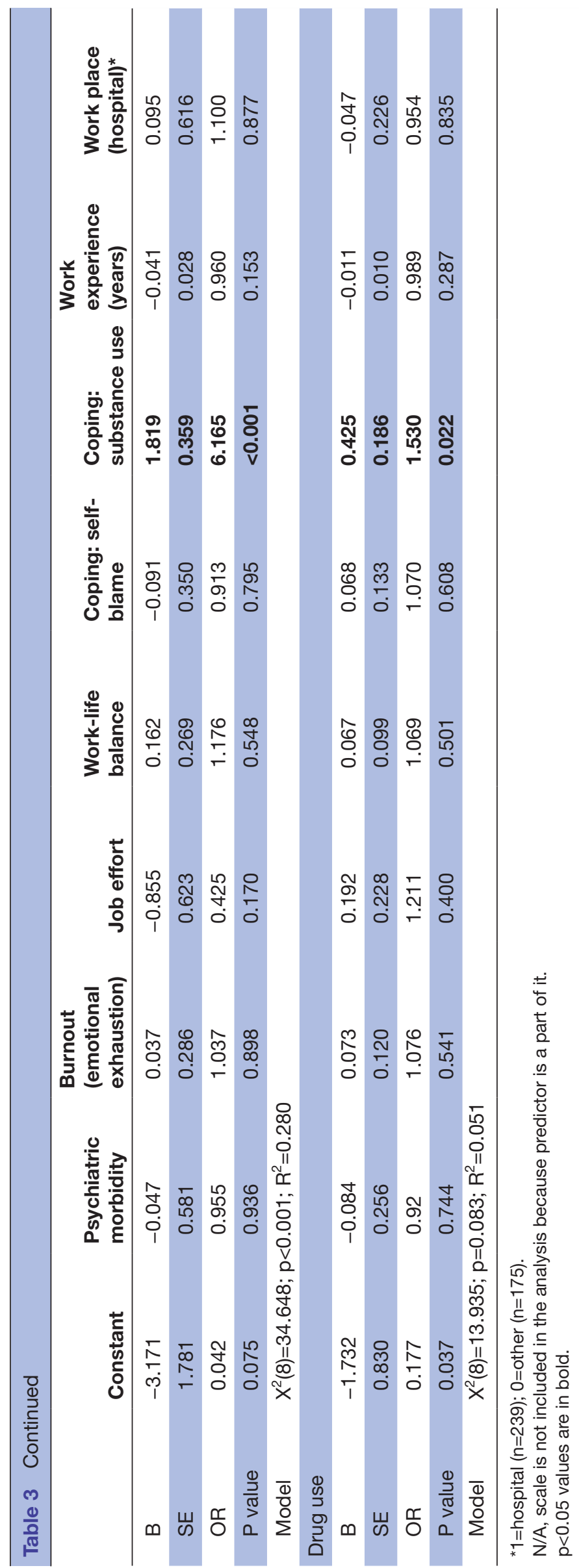

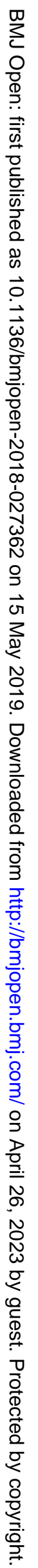


Table 4 Logistic regression predicting substance binge-eating problems

\begin{tabular}{|c|c|c|c|c|c|c|c|c|}
\hline Constant & $\begin{array}{l}\text { Psychiatric } \\
\text { morbidity }\end{array}$ & $\begin{array}{l}\text { Burnout } \\
\text { (emotional } \\
\text { exhaustion) }\end{array}$ & Job effort & $\begin{array}{l}\text { Work-life } \\
\text { balance }\end{array}$ & $\begin{array}{l}\text { Coping: } \\
\text { self-blame }\end{array}$ & $\begin{array}{l}\text { Coping: } \\
\text { substance } \\
\text { use }\end{array}$ & $\begin{array}{l}\text { Work } \\
\text { experience } \\
\text { (years) }\end{array}$ & $\begin{array}{l}\text { Work pl } \\
\text { (hospita }\end{array}$ \\
\hline \multicolumn{9}{|c|}{ amounts of food when not physically hungry } \\
\hline-1.831 & 0.344 & 0.127 & -0.403 & 0.176 & 0.410 & -0.094 & -0.022 & -0.040 \\
\hline 0.935 & 0.290 & 0.142 & 0.275 & 0.124 & 0.156 & 0.208 & 0.011 & 0.271 \\
\hline 0.160 & 1.410 & 1.136 & 0.669 & 1.193 & 1.507 & 0.910 & 0.978 & 0.961 \\
\hline 0.050 & 0.236 & 0.370 & 0.143 & 0.156 & 0.009 & 0.652 & 0.052 & 0.883 \\
\hline
\end{tabular}

Model $\quad X^{2}(8)=29.537 ; p<0.001 ; R^{2}=0.127$

Eat until feeling uncomfortably full

$\begin{array}{lcccccccccc}\text { B } & -2.229 & 0.064 & 0.132 & -0.186 & \mathbf{0 . 2 7 1} & 0.297 & -0.117 & -0.018 & -0.342 & 0.012 \\ \text { SE } & 0.972 & 0.294 & 0.144 & 0.278 & \mathbf{0 . 1 3 1} & 0.159 & 0.214 & 0.275 & 0.710 \\ \text { OR } & 0.108 & 1.066 & 1.141 & 0.831 & \mathbf{1 . 3 1 1} & 1.346 & 0.890 & 0.982 \\ \text { P value } & 0.022 & 0.828 & 0.359 & 0.504 & \mathbf{0 . 0 3 8} & 0.062 & 0.585 & 0.121 & 0.212\end{array}$

Model $\quad X^{2}(8)=22.420 ; p=0.004 ; R^{2}=0.100$

Eat alone because they feel embarrassed

$\begin{array}{lrrrrrrrrrr}\text { B } & -3.111 & 0.233 & 0.213 & -0.139 & 0.112 & 0.378 & 0.089 & -0.015 & -0.386 \\ \text { SE } & 1.068 & 0.314 & 0.158 & 0.307 & 0.139 & 0.175 & 0.220 & 0.013 & 0.300 \\ \text { OR } & 0.045 & 1.262 & 1.237 & 0.870 & 1.119 & 1.460 & 1.093 & 0.985 & 0.680 \\ \text { P value } & 0.004 & 0.458 & 0.178 & 0.650 & 0.418 & 0.031 & 0.686 & 0.255 & 0.199\end{array}$

Model $\quad X^{2}(8)=21.890 ; p=0.005 ; R^{2}=0.105$

Feel disgusted with themselves, depressed or very guilty after overeating

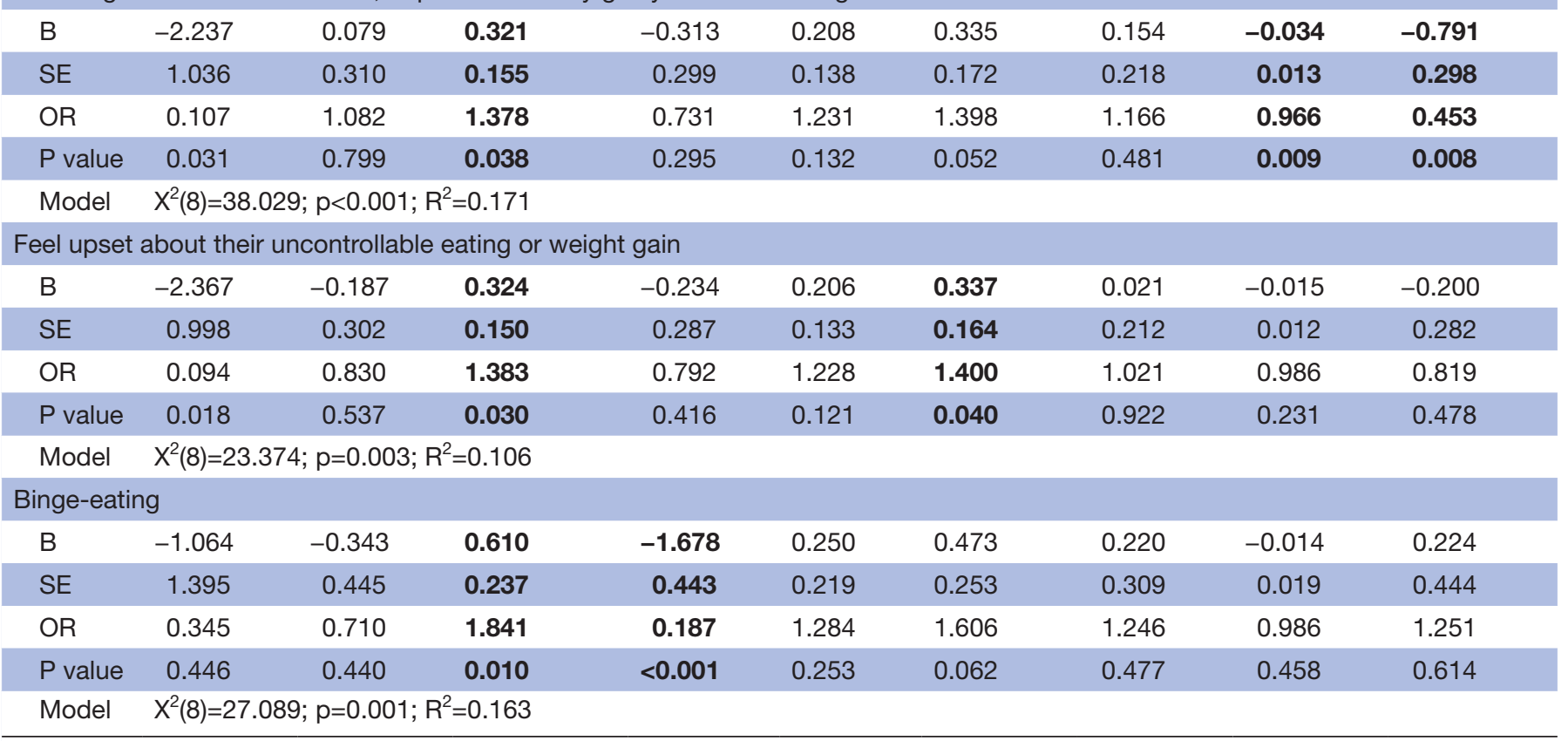

*1=hospital $(n=239) ; 0=$ other $(n=175)$.

$\mathrm{p}<0.05$ values are in bold.

that $11 \%$ of doctors have insomnia; $20 \%-61 \%$ experience various sleep problems; $5 \%$ are alcohol dependent; $27 \%-53 \%$ drink in a hazardous way; $69 \%$ have fatigue; 4\%-33\% experience other physical complaints; $8 \%$ have a binge-eating disorder and 24\%-35\% experience bingeeating symptoms. Forty-four per cent of doctors use some type of drugs, but mostly over-the-counter medications
$(35 \%)$. Prescription drug use was rare $(3 \%$ use opioids and $2 \%$ use benzodiazepines), suggesting that the proportion of doctors getting drug treatment for anxiety is lower than the proportion of doctors with anxiety $(14.7 \%) \cdot{ }^{40}$ Compared with the general population more doctors have psychiatric morbidity $(32.7 \%$ compared with $19 \%),{ }^{3}$ burnout $(55.3 \% \text { compared with } 24.8 \%)^{41}$ and 
Table 5 Logistic regression predicting sleep disturbances

\begin{tabular}{|llllllllll} 
& Constant & $\begin{array}{l}\text { Psychiatric } \\
\text { morbidity }\end{array}$ & $\begin{array}{l}\text { Burnout } \\
\text { (emotional } \\
\text { exhaustion) }\end{array}$ & Job effort & $\begin{array}{l}\text { Work-life } \\
\text { balance }\end{array}$ & $\begin{array}{l}\text { Coping: } \\
\text { self-blame }\end{array}$ & $\begin{array}{l}\text { Coping: } \\
\text { substance } \\
\text { use }\end{array}$ & $\begin{array}{l}\text { Work } \\
\text { experience Work } \\
\text { (years) }\end{array}$ & $\begin{array}{l}\text { Wospital) } \\
\text { (hosp }\end{array}$ \\
\hline Difficulty falling asleep & & & & & & & & & \\
B & -5.019 & $\mathbf{0 . 9 0 6}$ & $\mathbf{0 . 3 9 3}$ & -0.303 & 0.107 & -0.039 & $\mathbf{0 . 6 1 7}$ & -0.022 & $\mathbf{0 . 6 6 9}$ \\
$\mathrm{SE}$ & 1.098 & $\mathbf{0 . 3 0 4}$ & $\mathbf{0 . 1 5 8}$ & 0.313 & 0.139 & 0.171 & $\mathbf{0 . 2 1 0}$ & 0.013 & $\mathbf{0 . 3 0 8}$ \\
$\mathrm{OR}$ & 0.007 & $\mathbf{2 . 4 7 4}$ & $\mathbf{1 . 4 8 2}$ & 0.738 & 1.113 & 0.962 & $\mathbf{1 . 8 5 4}$ & 0.979 & $\mathbf{1 . 9 5 3}$ \\
$\mathrm{P}$ value & $<0.001$ & $\mathbf{0 . 0 0 3}$ & $\mathbf{0 . 0 1 3}$ & 0.333 & 0.443 & 0.822 & $\mathbf{0 . 0 0 3}$ & 0.103 & $\mathbf{0 . 0 3 0}$
\end{tabular}

Difficulty falling asleep

Model $\quad X^{2}(8)=65.69 ; p<0.001 ; R^{2}=0.249$

Difficulty staying asleep

$\begin{array}{lrllllllll}\text { B } & -5.593 & \mathbf{0 . 8 2 9} & \mathbf{0 . 4 6 8} & -0.022 & 0.038 & 0.155 & \mathbf{0 . 4 4 3} & 0.014 & 0.275 \\ \text { SE } & 1.014 & \mathbf{0 . 2 8 6} & \mathbf{0 . 1 3 7} & 0.267 & 0.114 & 0.148 & \mathbf{0 . 2 0 2} & 0.012 & 0.257 \\ \text { OR } & 0.004 & \mathbf{2 . 2 9 1} & \mathbf{1 . 5 9 6} & 0.978 & 1.039 & 1.168 & \mathbf{1 . 5 5 7} & 1.014 & 1.317 \\ \mathrm{P} \text { value } & <0.001 & \mathbf{0 . 0 0 4} & \mathbf{0 . 0 0 1} & 0.933 & 0.741 & 0.296 & \mathbf{0 . 0 2 8} & 0.233 & 0.285\end{array}$

Model $\quad X^{2}(8)=79.09 ; p<0.001 ; R^{2}=0.264$

Dissatisfied with sleep pattern

$\begin{array}{lrrrrrrrrr}\text { B } & -3.678 & \mathbf{0 . 9 6 2} & \mathbf{0 . 5 3 6} & -0.142 & -0.050 & -0.006 & 0.280 & -0.014 & 0.438 \\ \text { SE } & 0.937 & \mathbf{0 . 2 9 2} & \mathbf{0 . 1 3 4} & 0.256 & 0.108 & 0.143 & 0.200 & 0.011 & 0.250 \\ \text { OR } & 0.025 & \mathbf{2 . 6 1 7} & \mathbf{1 . 7 1 0} & 0.868 & 0.642 & 0.994 & 1.324 & 0.986 & 1.549 \\ \text { P value } & <0.001 & \mathbf{0 . 0 0 1} & <0.001 & 0.579 & 0.951 & 0.966 & 0.160 & 0.200 & 0.080\end{array}$

Model $\quad X^{2}(8)=85.18 ; p<0.001 ; R^{2}=0.274$

Sleep problems interfere with daily functioning

$\begin{array}{lccccccccc}\text { B } & -5.352 & \mathbf{1 . 0 4 7} & \mathbf{0 . 4 9 2} & -0.303 & 0.058 & \mathbf{0 . 3 4 7} & \mathbf{0 . 4 8 5} & -0.016 & 0.483 \\ \mathrm{SE} & 1.040 & \mathbf{0 . 2 9 9} & \mathbf{0 . 1 4 4} & 0.283 & 0.120 & \mathbf{0 . 1 5 3} & \mathbf{0 . 2 0 8} & 0.012 & 0.272 \\ \mathrm{OR} & 0.005 & \mathbf{2 . 8 4 8} & \mathbf{1 . 6 3 6} & 0.739 & 1.059 & \mathbf{1 . 4 1 4} & \mathbf{1 . 6 2 5} & 0.984 & 1.621 \\ \mathrm{P} \text { value } & <0.001 & <\mathbf{0 . 0 0 1} & \mathbf{0 . 0 0 1} & 0.284 & 0.631 & \mathbf{0 . 0 2 3} & \mathbf{0 . 0 1 9} & 0.187 & 0.075 \\ \text { Model } & \mathrm{X}^{2}(8)=102.74 ; \mathrm{p}<0.001 ; \mathrm{R}^{2}=0.333 & & & & & & \end{array}$

Worried or distressed about a current sleep problem

\begin{tabular}{|c|c|c|c|c|c|c|c|c|c|}
\hline B & -6.003 & 1.342 & 0.570 & -0.414 & 0.014 & 0.267 & -0.033 & $0-.013$ & 0.776 \\
\hline SE & 1.202 & 0.321 & 0.171 & 0.340 & 0.146 & 0.179 & 0.232 & 0.014 & 0.331 \\
\hline OR & 0.002 & 3.826 & 1.768 & 0.661 & 1.014 & 1.306 & 0.968 & 0.987 & 2.172 \\
\hline$P$ value & $<0.001$ & $<0.001$ & 0.001 & 0.224 & 0.924 & 0.136 & 0.888 & 0.362 & 0.019 \\
\hline Model & \multicolumn{9}{|c|}{$X^{2}(8)=86.58 ; p<0.001 ; R^{2}=0.327$} \\
\hline \multicolumn{10}{|c|}{ Think about work when they go to bed } \\
\hline B & -6.476 & 0.750 & 0.295 & 0.214 & 0.456 & 0.616 & -0.053 & -0.010 & 0.399 \\
\hline SE & 1.091 & 0.337 & 0.141 & 0.263 & 0.116 & 0.160 & 0.227 & 0.012 & 0.263 \\
\hline OR & 0.002 & 2.117 & 1.344 & 1.238 & 1.577 & 1.851 & 0.948 & 0.990 & 1.491 \\
\hline$P$ value & $<0.001$ & 0.026 & 0.036 & 0.416 & $<0.001$ & $<0.001$ & 0.814 & 0.393 & 0.128 \\
\hline Model & \multicolumn{9}{|c|}{$X^{2}(8)=128.23 ; p<0.001 ; R^{2}=0.391$} \\
\hline \multicolumn{10}{|c|}{ Trouble sleeping if they postpone tasks } \\
\hline B & -3.377 & 0.434 & 0.337 & -0.273 & 0.243 & 0.460 & 0.090 & -0.013 & 0.011 \\
\hline SE & 0.901 & 0.277 & 0.128 & 0.247 & 0.107 & 0.140 & 0.196 & 0.011 & 0.239 \\
\hline OR & 0.034 & 1.544 & 1.401 & 0.761 & 1.275 & 1.584 & 1.094 & 0.988 & 1.011 \\
\hline$P$ value & $<0.001$ & 0.117 & 0.008 & 0.270 & 0.023 & 0.001 & 0.648 & 0.237 & 0.965 \\
\hline Model & \multicolumn{9}{|c|}{$X^{2}(8)=72.32 ; p<0.001 ; R^{2}=0.234$} \\
\hline \multicolumn{10}{|l|}{ Insomnia } \\
\hline $\mathrm{B}$ & -8.627 & 1.458 & 0.597 & -0.109 & 0.035 & 0.346 & 0.148 & -0.025 & 0.802 \\
\hline SE & 1.600 & 0.378 & 0.216 & 0.433 & 0.191 & 0.226 & 0.270 & 0.018 & 0.417 \\
\hline
\end{tabular}

Continued 
Table 5 Continued

\begin{tabular}{|c|c|c|c|c|c|c|c|c|c|}
\hline & Constant & $\begin{array}{l}\text { Psychiatric } \\
\text { morbidity }\end{array}$ & $\begin{array}{l}\text { Burnout } \\
\text { (emotional } \\
\text { exhaustion) }\end{array}$ & Job effort & $\begin{array}{l}\text { Work-life } \\
\text { balance }\end{array}$ & $\begin{array}{l}\text { Coping: } \\
\text { self-blame }\end{array}$ & $\begin{array}{l}\text { Coping: } \\
\text { substance } \\
\text { use }\end{array}$ & $\begin{array}{l}\text { Work } \\
\text { experience } \\
\text { (years) }\end{array}$ & 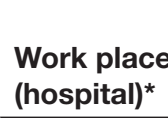 \\
\hline OR & $<0.001$ & 4.299 & 1.817 & 0.897 & 1.036 & 1.414 & 1.160 & 0.975 & 2.231 \\
\hline$P$ value & $<0.001$ & $<0.001$ & 0.006 & 0.802 & 0.854 & 0.126 & 0.582 & 0.162 & 0.054 \\
\hline Model & \multicolumn{9}{|c|}{$X^{2}(8)=78.24 ; p<0.001 ; R^{2}=0.360$} \\
\hline
\end{tabular}

${ }^{*} 1=$ hospital $(n=239) ; 0=$ other $(n=175)$.

$p<0.05$ values are in bold.

more doctors have physical complaints such as back pain (eg, 34\% compared with $8 \%-28 \%$ in the general population). ${ }^{42}$ However, fewer doctors have insomnia (11\%) or are alcohol dependent (5\%) compared with the general population, whereby $37 \%$ have insomnia and $13.9 \%-$ $29.1 \%$ have alcohol use disorder. ${ }^{43}$ The results from this study also revealed a higher prevalence of burnout than the National Trainee Survey which reported that 23.8\% of medical trainees have burnout ${ }^{44}$ but this could be because the current study had a high representation of consultants (49\%). The current study supports the recent BMA annual survey reporting that $61 \%$ of doctors feel that their stress levels have increased over the last year ${ }^{45}$ by showing that a similar proportion of doctors (55.3\%) have a type of burnout called emotional exhaustion.

\section{Occupational distress increases the odds of health problems among UK doctors}

The results show that occupational distress increases the odds of doctors using substances, having sleep disturbances, frequent symptoms of ill health and binge-eating. Even taking into consideration whether or not a doctor works in a hospital, the risk of health problems still rises when doctors have signs of occupational distress such as burnout. Previous research showed that distress, ${ }^{7} 4$ coping strategies ${ }^{47-49}$ and job factors ${ }^{50-55}$ are associated with health problems. This study replicates previous findings while demonstrating the generalisability of the effects to a wider range of health issues among UK doctors from various specialties.

\section{Alcohol/drug use}

Distressed doctors are more likely to use alcohol, with $22 \%-34 \%$ of doctors reporting that they use substances to feel better or help them get through stressful events. Doctors who cope with stress by using substances have a higher risk of alcohol dependence $(\mathrm{OR}=6.165)$, bingedrinking $(\mathrm{OR}=6.355)$, drinking larger amounts of alcohol $(\mathrm{OR}=2.599)$ and a higher risk of using alcohol more frequently $(\mathrm{OR}=18.836)$. Doctors who react to stress by blaming themselves are more likely to use substances to get through something $(\mathrm{OR}=1.374)$. Having more experience working in medicine makes a doctor more likely to drink alcohol frequently $(\mathrm{OR}=1.036)$ but lowers the likelihood of binge-drinking $(\mathrm{OR}=0.970)$. Doctors who work in a hospital are more likely to drink high amounts of alcohol on a typical day of drinking $(\mathrm{OR}=1.812)$ and to binge-drink ( $\mathrm{OR}=1.672)$. In understanding the effects of occupational distress on alcohol or drug use, the results showed the usefulness of assessing the combined effects of different types of occupational distress, but that, except for psychiatric morbidity, burnout, work-life imbalance and job effort do not individually predict alcohol use. This suggests that occupational distress is best understood as a syndrome when understanding its effect on alcohol use. These findings extend previous studies which show that burnout, depression and psychiatric morbidity individually predict using alcohol dependence/abuse. ${ }^{66}$ The results also show that-for UK doctors-occupational distress as a syndrome has no significant effect on legal or illegal drug use. Only doctors who cite substance use as a strategy that they use to cope with stress are significantly more likely to use drugs $(\mathrm{OR}=1.530)$ - and most of these are prescription or over-the-counter drugs.

\section{Binge-eating}

The risks of doctors binge-eating and experiencing negative emotions after over-eating are raised by occupational distress ( $\mathrm{OR}=1.311$ to 1.841$)$, for example, burnout, coping with stress by blaming oneself and work-life imbalance. This supports previous studies showing that bingeeating is a method of coping with stress that offers people an initial sense of comfort. ${ }^{14}{ }^{15}$ Doctors who have longer experience working in medicine, and doctors who work in hospitals, are less likely to have unpleasant emotions after binge-eating ( $\mathrm{OR}=0.966$ and 0.453$)$, suggesting that community-based doctors are more at risk of finding that binge-eating makes them feel worse, rather than better. The amount of effort that a doctor puts into their job lowers the risk of their suffering from a binge-eating disorder $(\mathrm{OR}=0.187)$. Psychiatric morbidity, by itself, did not predict binge-eating, and nor did coping with stress through substance use.

\section{Sleep disturbances}

Occupational distress and job factors significantly predict sleep problems and insomnia among doctors, supporting the view of occupational distress as a syndrome, while also revealing that certain types of occupational distress can also, individually, predict sleep disturbances. Previous research show that physicians with high burnout, for example, are more likely to experience sleep related 
Table 6 Logistic regression predicting ill health

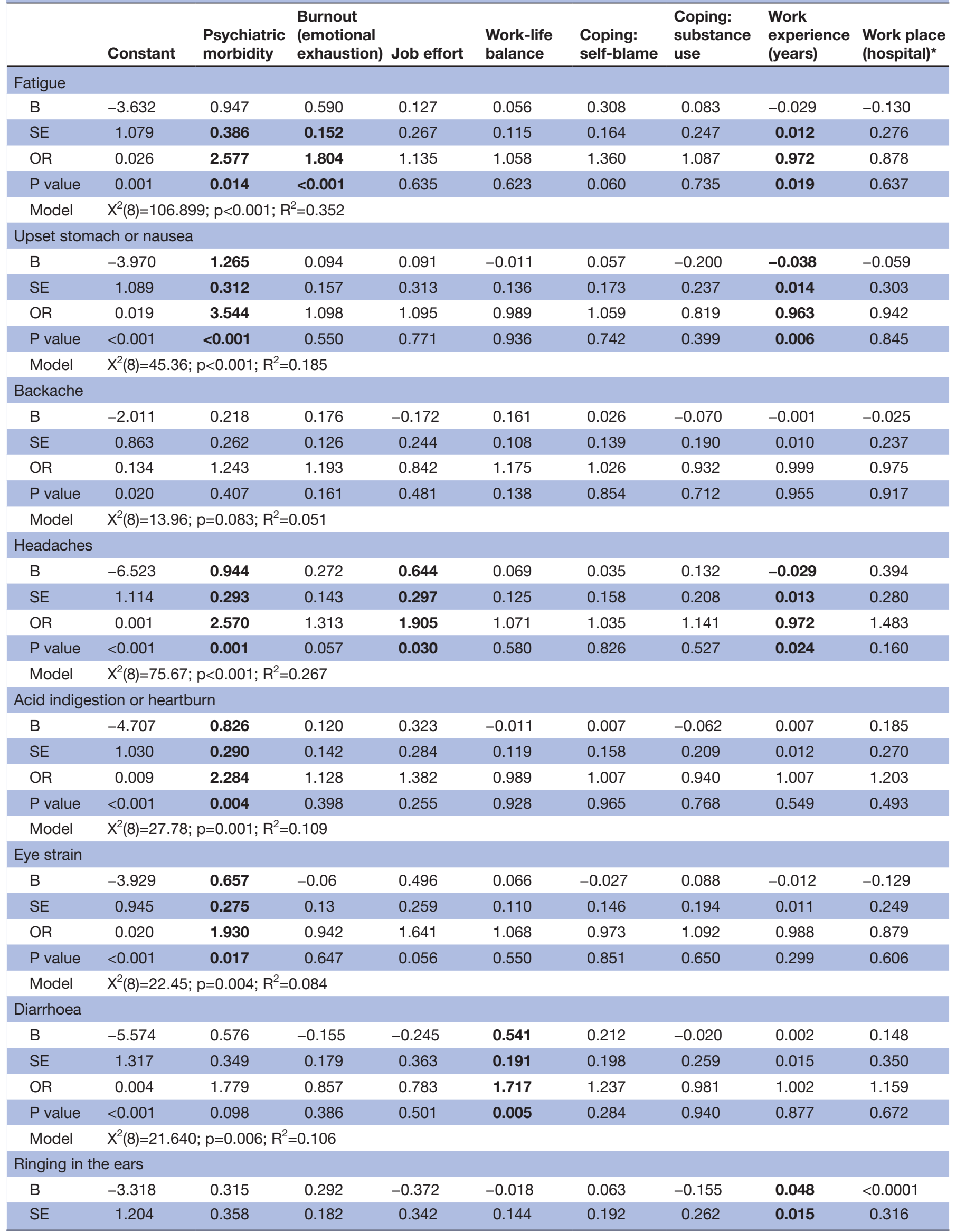


Table 6 Continued

\begin{tabular}{|c|c|c|c|c|c|c|c|c|c|}
\hline & Constant & $\begin{array}{l}\text { Psychiatric } \\
\text { morbidity }\end{array}$ & $\begin{array}{l}\text { Burnout } \\
\text { (emotional } \\
\text { exhaustion) }\end{array}$ & Job effort & $\begin{array}{l}\text { Work-life } \\
\text { balance }\end{array}$ & $\begin{array}{l}\text { Coping: } \\
\text { self-blame }\end{array}$ & $\begin{array}{l}\text { Coping: } \\
\text { substance } \\
\text { use }\end{array}$ & $\begin{array}{l}\text { Work } \\
\text { experience } \\
\text { (years) }\end{array}$ & $\begin{array}{l}\text { Work place } \\
\text { (hospital)* }^{\text {Whos }}\end{array}$ \\
\hline OR & 0.036 & 1.370 & 1.338 & 0.689 & 0.983 & 1.065 & 0.857 & 1.050 & 1.000 \\
\hline$P$ value & 0.006 & 0.379 & 0.109 & 0.277 & 0.903 & 0.742 & 0.555 & 0.002 & 1.000 \\
\hline Model & \multicolumn{9}{|c|}{$X^{2}(8)=16.817 ; p=0.032 ; R^{2}=0.080$} \\
\hline
\end{tabular}

${ }^{*} 1=$ hospital $(n=239) ; 0=$ other $(n=175)$.

$p<0.05$ values are in bold.

problems. ${ }^{57}$ This study extends our understanding of the risk factors and shows that burnout, psychiatric morbidity, maladaptive coping strategies, work-life imbalance and working in a hospital increase the risk of sleep disturbances $(\mathrm{OR}=1.344$ to 3.826$)$. This means that the risk of sleep problems or insomnia exists even if doctors are suffering from just one of these types of occupational distress, which is particularly noticeable with the increase in psychiatric morbidity. The sleep problems doctors experience include trouble falling/staying sleep, worrying about work when trying to sleep, and finding that sleep problems interfere with daily functioning.

\section{Daily or frequent ill health}

Occupational distress increases the odds of doctors suffering from fatigue, upset stomach or nausea, headaches, acid/indigestion or heartburn, eye strain, diarrhoea and ringing in the ears but not back pain. Psychiatric morbidity, burnout, coping with stress by blaming oneself, job effort and work-life imbalance each, as individual predictors, also raise the odds of doctors suffering from frequent ill health ( $\mathrm{OR}=1.050$ to 3.544). These findings extend previous studies which investigate how the working conditions experienced by doctors relate to ill health ${ }^{24}$ by showing that occupational distress, especially psychiatric morbidity, increases the risk of physical health problems. Doctors who work in a hospital do not have increased odds of ill health symptoms, and nor do doctors who use substances to cope with stress. More experienced doctors have lower odds of fatigue, upset stomach or nausea and headaches ( $\mathrm{OR}=0.963$ to 0.972$)$, but are at a greater risk of suffering from ringing ears $(\mathrm{OR}=1.050)$.

\section{Strengths and weaknesses of the study and future research}

This study is the first to explore the impact of occupational distress and work factors on the risk of health problems among UK doctors from various specialties. A weakness of this study is that the analysis is cross-sectional. We need future experimental research to test causation between occupational distress and health problems using a longitudinal design, and an evaluation of effect sizes using indicators such as Cohen's d. It was not possible to reliably convert odds ratios into Cohen's d within the current study because of the limitations of interpreting Cohen's $\mathrm{d}$ from data with dichotomous outcome variables. We also encourage future research to measure hypotheses that were not possible to test within the current study, for example, whether the risk of gastrointestinal problems among doctors rises with patient caseload or infection exposure.

It was not possible to calculate the response rate because it was not clear whether all NHS trusts and medical Royal Colleges who agreed to take part in this study actually distributed the invitation and to how many doctors. We are also mindful that some participants might not have been comfortable answering some sensitive questions (eg, about illicit drug or alcohol use), but the risk of response bias was mitigated by allowing doctors to complete confidential self-reported questionnaires. This is a recognised methods of measuring health and health-related behaviours (eg, alcohol intake ${ }^{58}$ ). We also recognise that using individual items from previously validated questionnaires (rather than all items) might have an impact on the validity and reliability of the measurement methods.

The meaning of the study: possible implications for clinicians and policymakers

Occupational distress among doctors has a detrimental effect on the quality of care and patient safety. ${ }^{1}$ This study has revealed that occupational distress also increases the risk of doctors suffering from health problems $(\mathrm{OR}=1.036$ to 18.836). The impact of occupational distress on ill health could increase levels of sickness-absence among doctors, thus reducing patient safety because of understaffing. Likewise, the impact of occupational distress on substance use and sleep problems could mean that distress indirectly impairs doctors' fitness to practise, judgement or decision-making because of being intoxicated, hung-over or having disturbed sleep. Therefore, we recommend that doctors' mentors, supervisors, peers and occupational health support services recognise and act on (1) the prevalence of occupational distress and health problems among doctors; (2) the possibility that occupational distress raises the risk of several health problems and (3) the need to provide early interventions that prevent doctors who are experiencing occupational distress from suffering the longterm health effects of sleep disturbances, frequent symptoms of ill health and adopting negative health behaviours, such as binge-drinking or eating in order to cope. 
Contributors AM and CK participated in the conception and design of the study. AM collected and analysed data. AM and CK were involved in the interpretation of the data and preparation of this article. Both authors read and approved the final manuscript.

Funding The authors have not declared a specific grant for this research from any funding agency in the public, commercial or not-for-profit sectors.

Competing interests None declared.

Ethics approval The BEI School Ethics Committee at Birkbeck, University of London, approved the study in May 2016. Participants voluntarily consented to take part in this study.

Provenance and peer review Not commissioned; externally peer reviewed.

Data sharing statement № additional unpublished data are available.

Open access This is an open access article distributed in accordance with the Creative Commons Attribution Non Commercial (CC BY-NC 4.0) license, which permits others to distribute, remix, adapt, build upon this work non-commercially, and license their derivative works on different terms, provided the original work is properly cited, appropriate credit is given, any changes made indicated, and the use is non-commercial. See: http://creativecommons.org/licenses/by-nc/4.0/.

\section{REFERENCES}

1. Panagioti M, Geraghty K, Johnson J, et al. Association between physician burnout and patient safety, professionalism, and patient satisfaction: A systematic review and meta-analysis. JAMA Intern Med 2018;178:1317-30.

2. Imo UO. Burnout and psychiatric morbidity among doctors in the UK: a systematic literature review of prevalence and associated factors. BJPsych Bull 2017;41:197-204.

3. Goodwin L, Ben-Zion I, Fear NT, et al. Are reports of psychological stress higher in occupational studies? A systematic review across occupational and population based studies. PLoS One 2013;8:e78693.

4. Medisauskaite A, Kamau C. Prevalence of oncologists in distress: Systematic review and meta-analysis. Psychooncology 2017;26:1732-40.

5. Hughes $\mathrm{PH}$, Brandenburg N, Baldwin DC, et al. Prevalence of substance use among US physicians. JAMA 1992;267:771-3.

6. Oreskovich MR, Kaups KL, Balch CM, et al. Prevalence of alcohol use disorders among American surgeons. Arch Surg 2012;147:168.

7. Ahola K, Honkonen T, Pirkola S, et al. Alcohol dependence in relation to burnout among the Finnish working population. Addiction 2006;101:1438-43.

8. Leiter MP, Hakanen JJ, Ahola K, et al. Organizational predictors and health consequences of changes in burnout: A 12-year cohort study. J Organ Behav 2012.

9. Merlo LJ, Gold MS. Prescription opioid abuse and dependence among physicians: hypotheses and treatment. Harv Rev Psychiatry 2008;16:181-94.

10. NHS. Alcohol misuse - NHS. https://www.nhs.uk/conditions/alcoholmisuse/ (accessed 26 Sep 2018).

11. NHS. Binge drinking - NHS. https://www.nhs.uk/live-well/alcoholsupport/binge-drinking-effects/ (accessed 26 Sep 2018).

12. Pena Gralle APB, Barbosa Moreno A, Lopes Juvanhol L, et al. Job strain and binge eating among Brazilian workers participating in the ELSA-Brasil study: does BMI matter? J Occup Health 2017;59:247-55.

13. Waller D. Binge eating. BMJ 2001;322:343

14. Macht M, Simons G. Emotions and eating in everyday life. Appetite 2000;35:65-71.

15. McManus F, Waller Glenn, Gi W. A functional analysis of bingeeating. Clin Psychol Rev 1995;15:845-63.

16. Kamau C. Safe working hours protect doctors from sleep deprivation. BMJ rapid response 2017:j4547.

17. Kalmbach DA, Arnedt JT, Song PX, et al. Sleep Disturbance and Short Sleep as Risk Factors for Depression and Perceived Medical Errors in First-Year Residents. Sleep 2017;40.

18. Eddy R. Sleep deprivation among physicians. B C Med J 2005;47:176-80.

19. Aldrees TM, Aleissa S, Zamakhshary M, et al. Physician well-being: prevalence of burnout and associated risk factors in a tertiary hospital, Riyadh, Saudi Arabia. Ann Saudi Med 2013;33:451-6.

20. Tobaldini E, Cogliati C, Fiorelli EM, et al. One night on-call: sleep deprivation affects cardiac autonomic control and inflammation in physicians. Eur J Intern Med 2013;24:664-70.
21. Anderson C, Sullivan JP, Flynn-Evans EE, et al. Deterioration of neurobehavioral performance in resident physicians during repeated exposure to extended duration work shifts. Sleep 2012;35:1137-46.

22. Bordley J, Agustin AG, Ahmed MA, et al. Restoration of resident sleep and wellness with block scheduling. Med Educ 2017;51:1241-9.

23. Cohen S, Williamson GM. Stress and infectious disease in humans. Psychol Bull 1991;109:5-24.

24. Vijendren A, Yung M, Sanchez J. Occupational health issues amongst UK doctors: a literature review. Occup Med 2015;65:519-28.

25. Spitzer RL, Williams JB, Kroenke K, et al. Validity and utility of the PRIME-MD patient health questionnaire in assessment of 3000 obstetric-gynecologic patients: the PRIME-MD Patient Health Questionnaire Obstetrics-Gynecology Study. Am J Obstet Gynecol 2000;183:759-69.

26. Babor TF, Higgins-Biddle JC, Saunders JB, et al. The Alcohol Use Disorders Identification Test Guidelines for Use in Primary Care. World Heal Organ 2001:pp1-40.

27. Carver CS. You want to measure coping but your protocol's too long: consider the brief COPE. Int J Behav Med 1997;4:92-100.

28. National Institute on Drug Abuse (NIDA). Commonly Abused Drugs Charts. 2016 https://www.drugabuse.gov/drugs-abuse/commonlyabused-drugs-charts (Accessed 16 Jan 2016).

29. Office for National Statistics. User Guide to Drug Misuse Statistics Contents, 2015.

30. Stice E, Telch CF, Rizvi SL. Development and validation of the Eating Disorder Diagnostic Scale: a brief self-report measure of anorexia, bulimia, and binge-eating disorder. Psychol Assess 2000;12:123-31.

31. Bastien $\mathrm{CH}$, Vallières $\mathrm{A}$, Morin $\mathrm{CM}$. Validation of the Insomnia Severity Index as an outcome measure for insomnia research. Sleep Med 2001;2:297-307.

32. Siegrist J, Li J, Montano D. Psychometric properties of the effortreward imbalance questionnaire. Germany 2014. http://www. uniklinik-duesseldorf.de/fileadmin/Datenpool/einrichtungen/institut fuer_medizinische_soziologie_id54/ERI/Psychometrie.pdf.

33. Spector PE, Jex SM. Development of four self-report measures of job stressors and strain: Interpersonal Conflict at Work Scale, Organizational Constraints Scale, Quantitative Workload Inventory, and Physical Symptoms Inventory. J Occup Health Psychol 1998;3:356-67.

34. Goldberg DP, Hillier VF. A scaled version of the General Health Questionnaire. Psychol Med 1979;9:139-45.

35. Maslach C, Jackson SE. The measurement of experienced burnout. J Organ Behav 1981;2:99-113.

36. Maslach C, Leiter MP. Understanding the burnout experience: recent research and its implications for psychiatry. World Psychiatry 2016;15:103-11.

37. Netemeyer RG, Boles JS, McMurrian R. Development and validation of work-family conflict and family-work conflict scales. J Appl Psychol 1996;81:400-10.

38. General Medical Council. The state of medical education and practice in the UK, 2017

39. General Medical Council. Data Explorer. https://data.gmc-uk.org/ gmcdata/home/\#/reports (Accessed 24 Nov 2018)

40. Johansson R, Carlbring P, Heedman $\AA$, et al. Depression, anxiety and their comorbidity in the Swedish general population: point prevalence and the effect on health-related quality of life. PeerJ 2013;1:e98.

41. Shanafelt TD, Hasan O, Dyrbye LN, et al. Changes in Burnout and Satisfaction With Work-Life Balance in Physicians and the General US Working Population Between 2011 and 2014. Mayo Clin Proc 2015;90:1600-13.

42. Health \& Safety Executive. The role of work stress and psychological factors in the development of musculoskeletal disorders. 2004. http://www.hse.gov.uk/research/rrpdf/rr273.pdf (Accessed 5 May 2018).

43. Grant BF, Goldstein RB, Saha TD, et al. Epidemiology of DSM-5 Alcohol Use Disorder. JAMA Psychiatry 2015;72:757.

44. General Medical Council. National training surveys 2018: Initial findings report. 2018:1-16 https://www.gmc-uk.org/-/media/ documents/dc11391-nts-2018-initial-findings-report_pdf-75268532. pdf.

45. BMA. BMA quarterly tracker survey. 2017. BMA Surv Published Online First. http://bma.org.uk/working-for-change/policy-andlobbying/training-and-workforce/tracker-survey/omnibus-augustsurvey-2014.

46. Davey MM, Cummings G, Newburn-Cook CV, et al. Predictors of nurse absenteeism in hospitals: a systematic review. J Nurs Manag 2009;17:312-30. 
47. Kataoka M, Ozawa K, Tomotake M, et al. Occupational stress and its related factors among university teachers in Japan. Health 2014;06:299-305.

48. Litman JA. The COPE inventory: Dimensionality and relationships with approach- and avoidance-motives and positive and negative traits. Pers Individ Dif 2006;41:273-84.

49. Mark G, Smith AP. Occupational stress, job characteristics, coping, and the mental health of nurses. Br J Health Psychol 2012;17:505-21.

50. Khan A, Teoh KR, Islam S, et al. Psychosocial work characteristics, burnout, psychological morbidity symptoms and early retirement intentions: a cross-sectional study of NHS consultants in the UK. BMJ Open 2018;8:e018720.

51. Lee RT, Seo B, Hladkyj S, et al. Correlates of physician burnout across regions and specialties: a meta-analysis. Hum Resour Health 2013;11:48.

52. Umene-Nakano W, Kato TA, Kikuchi S, et al. Nationwide Survey of Work Environment, Work-Life Balance and Burnout among Psychiatrists in Japan. PLoS One 2013;8:e55189-8.
53. Keller M, Bamberg E, Kersten M, et al. Instrument for stress-related job analysis for hospital physicians: validation of a short version. $J$ Occup Med Toxicol 2013;8:10-20.

54. Shirom A, Nirel N, Vinokur AD. Work hours and caseload as predictors of physician burnout: The mediating effects by perceived workload and by autonomy. Appl Psychol 2010;59:539-65.

55. Wen J, Cheng Y, Hu X, et al. Workload, burnout, and medical mistakes among physicians in China: A cross-sectional study. Biosci Trends 2016;10:27-33.

56. Taylor C, Graham J, Potts H, et al. Impact of hospital consultants poor mental health on patient care. British Journal of Psychiatry 2007:190:268-9.

57. Vela-Bueno A, Moreno-Jiménez B, Rodríguez-Muñoz A, et al. Insomnia and sleep quality among primary care physicians with low and high burnout levels. J Psychosom Res 2008;64:435-42.

58. Giovannucci E, Colditz G, Stampfer MJ, et al. The assessment of alcohol consumption by a simple self-administered questionnaire. Am J Epidemiol 1991;133:810-7. 